\title{
EFFECT OF MANDUCA SEXTA DIURETIC HORMONE AND RELATED PEPTIDES ON ISOLATED MALPIGHIAN TUBULES OF THE HOUSE CRICKET ACHETA DOMESTICUS (L.)
}

\author{
BY GEOFFREY M. COAST ${ }^{1}$, TIMOTHY K. HAYES ${ }^{2}$, IAIN KAY ${ }^{1}$ AND \\ JUM-SOOK CHUNG ${ }^{1}$ \\ ${ }^{1}$ Department of Biology, Birkbeck College, London WC1E 7HX, UK and \\ ${ }^{2}$ Department of Entomology, Texas $A \& M$ University, College Station, TX \\ 77843, USA
}

Accepted 5 September 1991

\begin{abstract}
Summary
Previously, a corticotropin releasing factor (CRF)-like diuretic peptide (Manduca-DH) has been isolated from Manduca sexta and shown to stimulate fluid excretion in vivo in post-eclosion Pieris rapae adults and in pre-wandering postfeeding Manduca sexta larvae. However, Manduca-DH was reported to have no effect on Malpighian tubules in vitro.

Manduca-DH and [Nle $\left.{ }_{2,11}\right]-$ Manduca-DH were synthesized in Texas and assayed in London on isolated Malpighian tubules of Acheta domesticus. Manduca-DH stimulated fluid secretion by about $60 \%$ of the maximum response achievable with extracts of corpora cardiaca and increased the production of cyclic AMP. In combination with $10^{-4} \mathrm{moll}^{-1} 3$-isobutyl-1-methyl xanthine (IBMX), Manduca-DH stimulated maximal secretion. A number of CRF-related peptides also stimulated fluid secretion and cyclic AMP production in cricket tubules, and the CRF antagonist $\alpha$-helical- $\mathrm{CRF}_{[9-41]}$ blocked the stimulation of fluid secretion by Manduca-DH. $\left[\mathrm{Nle}_{2,11}\right]-$ Manduca-DH was more active than Manduca-DH in both assays, suggesting that methionine residues in the natural peptide may become oxidized.

Taken in conjunction with previous in vivo studies, the present findings suggest that a Manduca-DH-like diuretic peptide is the hormone controlling post-eclosion diuresis in butterflies, and Manduca-DH was shown to stimulate both fluid secretion and cyclic AMP production in Malpighian tubules from 1-12 $\mathrm{h}$ posteclosion Pieris rapae adults. The function of the peptide in Manduca sexta is discussed.
\end{abstract}

\section{Introduction}

Kataoka et al. (1989) identified a 41-residue diuretic peptide (Manduca-diuretic hormone; Manduca-DH) from Manduca sexta, which resembles vertebrate

Key words: diuretic hormone, Malpighian tubules, fluid secretion, cyclic AMP, Manduca sexta, Pieris rapae, Acheta domesticus. 
neuropeptides of the corticotropin releasing factor (CRF) family. Synthetic Manduca-DH stimulated fluid excretion in vivo in head-ligated post-eclosion Pieris rapae adults and a pronounced loss of fluid through the gut and the epidermis in pre-wandering post-feeding Manduca sexta larvae. Malpighian tubules are generally the primary target for diuretic hormones, but Kataoka et al. (1989) found that Manduca-DH did not have a direct effect on isolated tubules of Manduca sexta larvae, and suggested that the peptide may release a 'true' diuretic hormone. This is an interesting suggestion, given that CRF stimulates the release of adrenocorticotropic hormone (ACTH) from the vertebrate pituitary, and Rafaeli et al. (1986) found that ACTH stimulates cyclic AMP production and fluid secretion by isolated Malpighian tubules of Locusta migratoria.

\section{Materials and methods}

\section{Animals}

Malpighian tubules from adult virgin female Acheta domesticus (Linnaeus) 1-2 weeks old were used in the majority of experiments. Crickets were maintained and reared as previously described (Clifford et al. 1977; Coast, 1988) and were fed on a diet of turkey starter crumbs with water provided ad libitum. In one set of experiments, Malpighian tubules from 1-12 h post-eclosion Pieris rapae adults were used. Pieris rapae pupae were obtained from Professor L. M. Schoonhoven (The Netherlands).

\section{Peptide synthesis}

Manduca-DH and a chemically more stable analogue in which methionine at residues 2 and 11 was replaced by norleucine ([Nle $\left.{ }_{2,11}\right]$-Manduca-DH) were synthesized in Texas with tBoc solid-phase peptide chemistry using methods similar to those employed by Kataoka et al. (1989). Final cleavage-deprotection of Manduca-DH was by low-high hydrofluoric acid (HF) cleavage (Tam et al. 1983). The cleavage of both peptides was with the scavenger-HF mixture $(1.5 \mathrm{ml}$ of anisole: $500 \mu \mathrm{l}$ of ethanedithiol: $10 \mathrm{ml}$ of liquid HF per gram of resin) for $2 \mathrm{~h}$ at $-15^{\circ} \mathrm{C}$. The temperature was raised to $0^{\circ} \mathrm{C}$ for $45 \mathrm{~min}$ to ensure removal of tosyl groups from arginine side chains. Analytical HPLC immediately after preparative HPLC showed the chosen fractions to be homogeneous. Peptides were quantified by PicoTag amino acid analysis (Cohen et al. 1984) and the amino acid composition and mass, determined by fast atom bombardment mass spectrometry, were consistent with the target sequences. Samples were dried by vacuum centrifugation for transatlantic shipment.

\section{Bioassays}

In London, the peptides were redissolved in methanol at $10^{-5} \mathrm{moll}^{-1}$ and stored at $-20^{\circ} \mathrm{C}$. Prior to assay, samples were transferred to polypropylene centrifuge tubes containing $12.5 \mu \mathrm{g}$ of gamma globulin and taken to dryness in a vacuum 
centrifuge. Test material was resuspended in Acheta domesticus saline (Coast, 1988) and assayed for its ability to stimulate fluid secretion and cyclic AMP production by isolated Malpighian tubules of Acheta domesticus. These bioassays have been described in detail elsewhere (Coast, 1988; Coast et al. 1991; Kay et al. 1991). Fluid secretion was measured over $40 \mathrm{~min}$ periods before and after the addition of assay material. Diuretic activity was determined as the increase in rate of secretion compared with controls (Ringer substitution) and expressed as a percentage of the response to a supramaximal amount of corpora cardiaca extract (5 gland pairs per $50 \mu \mathrm{l}$; Coast and Wheeler, 1990). Cyclic AMP production was determined in groups of 4-5 tubules incubated at room temperature in Ringer containing $10^{-4} \mathrm{~mol}^{-1} 3$-isobutyl-1-methyl xanthine (IBMX) to inhibit phosphodiesterase activity. Reactions were stopped after $30 \mathrm{~min}$ by the addition of ice-cold methanol and the cyclic AMP released by sonication was measured using a competitive protein binding assay (Coast et al. 1991). Additionally, Manduca-DH was assayed for its ability to stimulate fluid secretion and cyclic AMP production by isolated Malpighian tubules of Pieris rapae using identical methods to those employed with cricket tubules, but with the saline of Nicolson (1976a).

\section{Chemicals}

Synthetic bovine CRF, sucker fish urotensin-I, sauvagine, bovine gamma globulin and IBMX were obtained from Sigma.

\section{Statistics}

All data are presented as mean \pm standard error (S.E.). Student's $t$-test was used to determine significant differences in fluid secretion and cyclic AMP production caused by peptide addition. Values for $t$ and degrees of freedom (d.f.) are given, with $P<0.05$ accepted as significant. Dose-response curves were analysed using the Maximum Likelihood Program (Numerical Algorithms Group Ltd).

\section{Results and discussion}

Within $2 \mathrm{~min}$ of the addition of $10^{-6} \mathrm{moll}^{-1}$ Manduca-DH there was a significant increase in fluid secretion $(t=3.011$; d.f. $=13 ; P<0.01)$, and the response peaked after $15 \mathrm{~min}$ (Fig. 1A). The dose-response curve for the effect of Manduca-DH on fluid secretion (Fig. 2A) appeared truncated and saturated at about $60 \%$ of the maximum response achievable with extracts of corpora cardiaca. Analysis of the dose-response curve gave an $\mathrm{EC}_{50}$ of $1.3 \times 10^{-6} \pm 0.2 \times 10^{-6} \mathrm{~mol}^{-1}$. In Manduca sexta, an $\mathrm{EC}_{50}$ of $0.02 \mathrm{pmol}$ of injected peptide was cited by Kataoka et al. (1989) which, with a haemolymph volume of approximately $1 \mathrm{ml}$ (S. E. Reynolds, personal communication), is equivalent to about $2 \times 10^{-11} \mathrm{moll}^{-1}$. Thus, the peptide is about five orders of magnitude more potent in Manduca sexta than in Acheta domesticus. Addition of $10^{-4} \mathrm{moll}^{-1}$ IBMX displaced the dose-response curve to the left (Fig. $2 \mathrm{~A} ; E_{50}=$ $5.4 \times 10^{-7} \pm 0.6 \times 10^{-7} \mathrm{moll}^{-1}$ ), and the diuretic activity of $10^{-6} \mathrm{moll}^{-1}$ Manduca- 

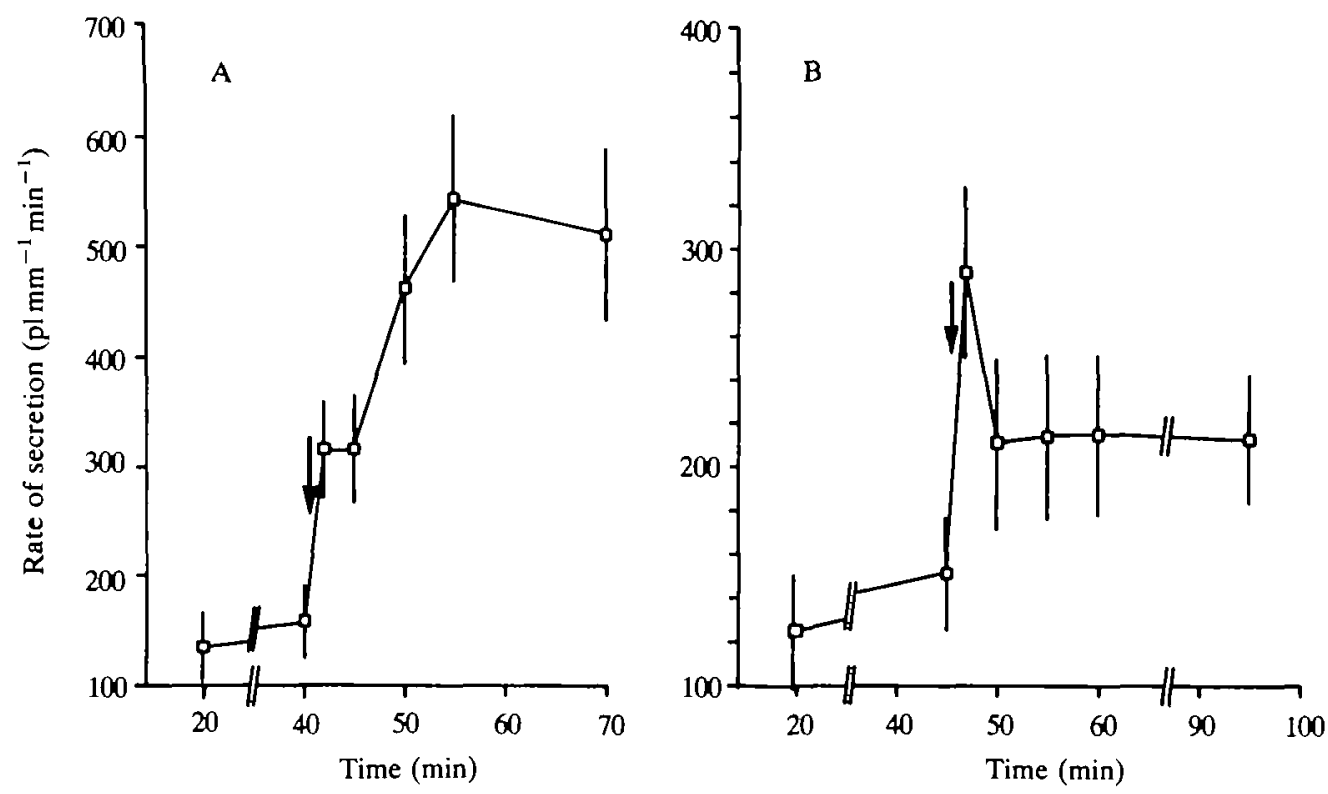

Fig. 1. Stimulation of tubule fluid secretion by (A) $10^{-6} \mathrm{~mol}^{-1}$ Manduca-DH and (B) $5 \times 10^{-6} \mathrm{moll}^{-1}$ urotensin-I. Points represent the means of 6-8 determinations and vertical lines are \pm 1 s.e. The time of addition of the peptides is shown by the arrows. Note the difference in scale of the $y$-axis in the two graphs.

DH did not differ significantly $(t=0.799$; d.f. $=15 ; P=0.442)$ from the maximum (IBMX alone increased fluid secretion by $16 \pm 2.4 \%$ of maximum). This suggested that the peptide stimulated adenylyl cyclase. $10^{-6} \mathrm{moll}^{-1}$ Manduca-DH significantly $(t=19.117$; d.f. $=10 ; P \ll 0.001)$ increased the production of cyclic AMP by isolated Malpighian tubules (Fig. 3).

Some CRF-related peptides (Table 1) were also assayed. Kataoka et al. (1989) showed that injection of $500 \mathrm{pmol}$ of CRF, urotensin-I or sauvagine had no effect

Table 1. Amino acid sequences of Manduca-DH and the CRF-related peptides used in this study

\section{Manduca-DH}

R M PSLSIDLPMSVLR QKLSLEKERK V H A L R A A NR NFL N I-NH

Sucker fish urotensin-1

NDDPPISIDLTFHLLR NMIEM ARIENEQA GLNRK YLDEV-NH

Sauvagine

PQ G P P I L D L TFH L LRE VLEMTKA D Q L A Q A H N R K LLDI A-NH Bovine-CRF

S QEP PIS L D L T F L LREVLEMTKA D Q LA Q QAHNNRKLLDIA-NH $\alpha$-helical $\mathrm{CRF}_{[9-41]}$

DLTFHLLREMLEM A K A E Q A E Q A A L N R L L LE E A-NH 

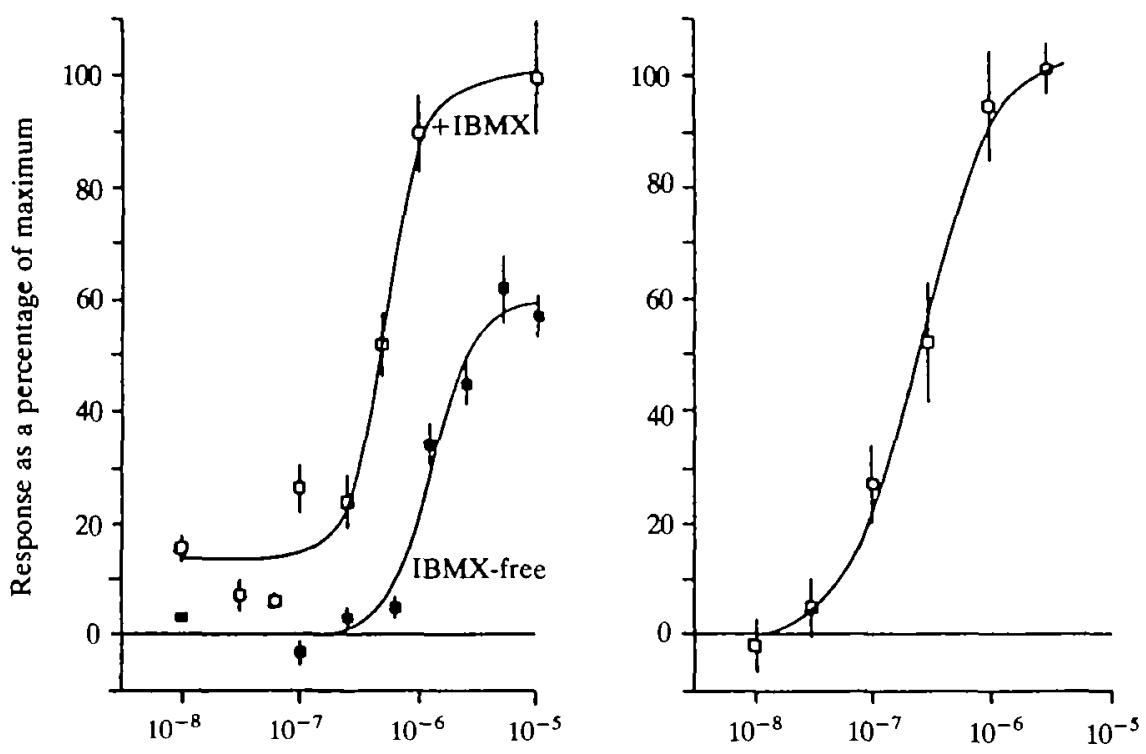

Dose $\left(\mathrm{moll}^{-1}\right)$

Fig. 2. Dose-response curves for the diuretic activities of (A) Manduca-DH alone ( $\mathbf{\square})$ and in the presence of $10^{-4} \mathrm{moll}^{-1}$ IBMX ( $\square$ ), and (B) [Nle 2,11$]-$ Manduca-DH. Diuretic activity is expressed as a percentage of the response to an extract of corpora cardiaca that elicits a maximal stimulation. Points represent the means of 5-10 determinations, and vertical lines are \pm 1 s.E.

on fluid excretion by head-ligated post-eclosion Pieris rapae adults. At $5 \times 10^{-6} \mathrm{moll}^{-1}$, urotensin-I brought about a significant stimulation of fluid secretion by Acheta domesticus tubules after $2 \min (t=2.550$; d.f. $=11 ; P<0.05)$, but this was not sustained (Fig. 1B). Urotensin-I, sauvagine and CRF all stimulated fluid secretion in a dose-dependent fashion (results not shown), but the responses did not saturate. At $10^{-5} \mathrm{moll}^{-1}$, all three peptides increased fluid secretion by about $20 \%$ of the maximum. Ovine CRF stimulates adenylyl cyclase in the pituitary (Labrie et al. 1983) and $10^{-6} \mathrm{moll}^{-1}$ urotensin-I, sauvagine and CRF all elicited small increases in cyclic AMP production in cricket tubules (Fig. 3). The CRF antagonist $\alpha$-helical-CRF ${ }_{[9-41]}$ (Rivier et al. 1984) had no significant effect either on cyclic AMP production (Fig. 3) or on fluid secretion $(t=0.241 ;$ d.f. $=11 ; P=0.192)$. Manduca-DH $\left(10^{-6} \mathrm{~mol} \mathrm{l}^{-1}\right)$ was assayed alone and together with $\mathrm{CRF}$ antagonist. Manduca-DH alone increased fluid secretion by $114 \pm 19.2 \mathrm{pl} \mathrm{mm}^{-1} \min ^{-1}(N=7)$. At $10^{-4} \mathrm{moll}^{-1}, \alpha$-helical-CRF $\mathrm{C}_{[-41]}$ blocked the response, the difference between the control and experimental rates being $-47 \pm 53.8 \mathrm{pl} \mathrm{mm}{ }^{-1} \mathrm{~min}^{-1}(N=6)$. Lower concentrations of the antagonist were without effect.

The [Nle $\left.{ }_{2,11}\right]-$ Manduca-DH analogue stimulated cyclic AMP production to a greater extent than did Manduca-DH (Fig. 3) and was more active in the fluid secretion assay, giving a maximum response without the addition of IBMX 


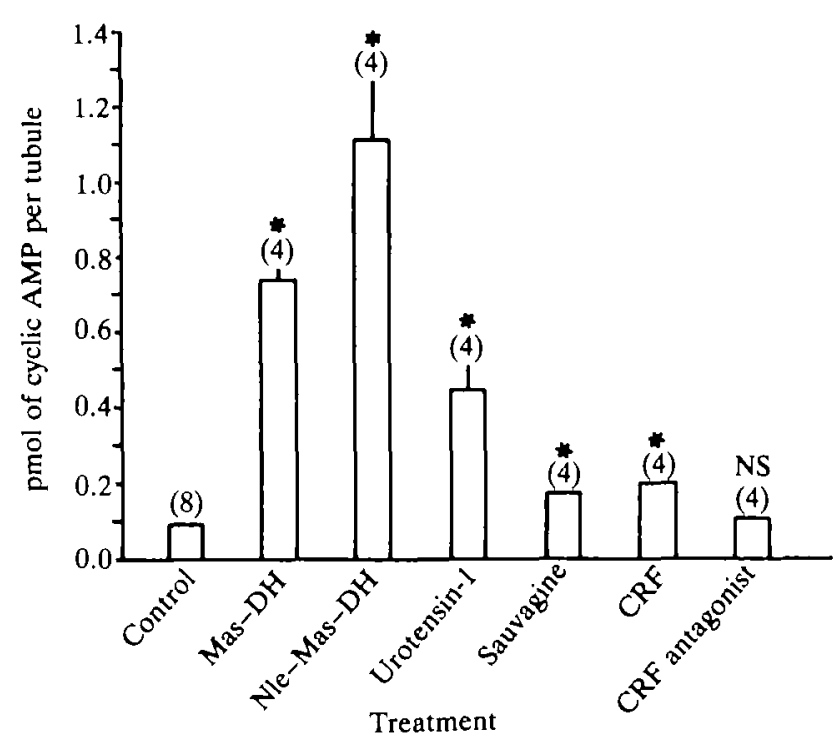

Fig. 3. The effect of $10^{-6} \mathrm{moll}^{-1}$ Manduca-DH and related peptides on cyclic AMP production by isolated Malpighian tubules. Results are expressed as pmol of cyclic AMP produced per tubule over a $30 \mathrm{~min}$ incubation. Bars represent the means of the number of determinations given in parentheses and vertical lines $+1 \mathrm{~s}$. E. Student's $t$-test was used to compare results with those from control incubations (Ringer addition). Asterisks denote $P<0.001$; NS, not significant. Manduca-DH, Mas-DH; [Nle $\left.{ }_{2,11}\right]$-Manduca-DH, Nle-Mas-DH; CRF, corticotropin releasing factor.

$\left(\mathrm{EC}_{50}=2.8 \times 10^{-7} \pm 0.8 \times 10^{-7} \mathrm{moll}^{-1}\right.$; Fig. 2B). Methionine residues in ManducaDH may, therefore, be prone to oxidation. A sample of synthetic Manduca-DH from Peninsula Laboratories Inc. gave a truncated dose-response curve in the fluid secretion assay and saturated at $69 \%$ of maximum, somewhat higher than that for the peptide synthesized by us ( $60 \%$ of maximum), but lower than that for $\left[\mathrm{Nle}_{2,11}\right]-$ Manduca-DH. The material from Peninsula Laboratories was also about 10 times more potent $\left(\mathrm{EC}_{50}=1.6 \times 10^{-7} \pm 0.4 \times 10^{-7} \mathrm{moll}^{-1}\right)$. Such differences may reflect the extent to which oxidation had occurred.

Because Manduca-DH acts directly on cricket tubules it is unlikely to be a releasing factor in the host species. In Pieris brassicae, post-eclosion diuresis is stimulated by a peptide from the brain and the retrocerebral complex working via cyclic AMP to increase tubule fluid secretion (Nicolson, 1976a,b). Manduca-DH stimulates fluid excretion in post-eclosion Pieris rapae adults and, when assayed at $10^{-6} \mathrm{moll}^{-1}$ on Malpighian tubules taken from adult butterflies within $1-12 \mathrm{~h}$ of eclosion, it increased fluid secretion by $196 \pm 26.1 \% \quad(t=5.793$; d.f. $=11 ; P<0.001)$ and cyclic AMP production from $1.6 \pm 0.22$ to $4.3 \pm 0.37$ pmol per tubule $(t=6.309$; d.f. $=8 ; P<0.001$ ). Thus, a Manduca-like peptide is probably the hormone controlling post-eclosion diuresis in butterflies. In Manduca sexta, weight loss occurs largely during the $48 \mathrm{~h}$ preceding pupation (Baker et al. 1987). However, at 
this time, Manduca sexta tubules lose their ability to excrete dyes (Nijhout, 1975), and fluid secretion may be switched off prior to the end of the stadium (Nicolson, 1976b; Ryerse, 1978; Chung and Keeley, 1989). Reabsorption of fluid from the rectum of Manduca sexta larvae might be subject to neural or hormonal control (Reynolds and Bellward, 1989). Thus, Manduca-DH could act in vivo to inhibit fluid uptake from the rectum in the period before tubule secretion is switched off, so increasing faecal water loss.

Manduca-DH belongs to a family of insect diuretic peptides that are themselves members of a superfamily of peptides including CRF, sauvagine and urotensin-I (G. M. Coast, G. J. Goldsworthy, M. S. Johnson, I. Kay and C. H. Wheeler, in preparation). These peptides are involved, either directly or indirectly, in the regulation of hydromineral balance, and all appear to act via cyclic AMP. They are sufficiently similar for there to be discernible cross-reactivity in Acheta domesticus tubules. As in vertebrates, $\alpha$-helical $\mathrm{CRF}_{[9-41]}$ appears to be an antagonist, and the amino terminal region of the peptides may be important for signal transduction. This could explain differences in activity between Manduca-DH and [Nle ${ }_{2,11}$ ]Manduca-DH.

The work at Birkbeck was supported by a grant from the AFRC, and at Texas A \& M by an NSF grant (DCB-8918438) and the Tamu Biotechnology Support Laboratory which provided the instrumentation. We thank Alan Tyler for his technical assistance and Graham Goldsworthy for comments on a final draft of this manuscript.

\section{References}

BAKer, F. C., TSAI, L. W., ReuTer, C. C. AND SCHOOLEY, D. A. (1987). In vivo fluctuation of $\mathrm{JH}, \mathrm{JH}$ acid, and ecdysteroid titer, and $\mathrm{JH}$ esterase activity, during development of fifth stadium Manduca sexta. Insect Biochem. 17, 989-996.

Chung, J.-S. ANd KeEley, L. L. (1989). Evidence and bioassay for diuretic factors in the nervous system of larval Heliothis virescens. J. comp. Physiol. B 159, 359-370.

Clifford, C. W., Roe, R. M. And Woodring, J. P. (1977). Rearing methods for obtaining house crickets, Acheta domesticus, of known age, sex and instar. Ann. ent. Soc. Am. 70, $69-74$.

COAST, G. M. (1988). Fluid secretion by single isolated Malpighian tubules of the house cricket, Acheta domesticus, and their response to diuretic hormone. Physiol. Ent. 13, 381-391.

Coast, G. M., Cusinato, O., Kay, I. and Goldsworthy, G. J. (1991). An evaluation of the role of cyclic AMP as an intracellular messenger in Malpighian tubules of the house cricket, Acheta domesticus. J. Insect Physiol. (in press).

COAST, G. M. AND WheELER, C. H. (1990). The distribution and relative potency of diuretic peptides in the house cricket, Acheta domesticus. Physiol. Ent. 15, 13-21.

Cohen, S. A., Tarvin, T. L. And Bidlingmeyer, B. A. (1984). Analysis of amino acids using precolumn derivitization with phenylthioisocyanate. Am. Lab. 16, 48-59.

Kataoka, H., Troetschler, R. G., Li, J. P., Kramer, S. J., Carney, R. L. and Schooley, D. A. (1989). Isolation and identification of a diuretic hormone from the tobacco hornworm, Manduca sexta. Proc. natn. Acad. Sci. U.S.A. 86, 2976-2980.

Kay, I., Coast, G. M., Cusinato, O., Wheeler, C. H., Totty, N. F. and Goldsworthy, G. J. (1991). Isolation and characterization of a diuretic peptide from Acheta domesticus: evidence for a family of insect diuretic peptides. Biol. Chem. Hoppe-Seyler 372, 505-512. 
Labrie, F., Gagne, B., Lefevre, G. and Meunier, H. (1983). CRF stimulates adenylate cyclase activity in the intermediate lobe of the pituitary gland. Molec. cell. Endocr. 30, 347-351.

Nicolson, S. W. (1976a). Diuresis in the cabbage white butterfly, Pieris brassicae: fluid secretion by the Malpighian tubules. J. Insect Physiol. 22, 1347-1356.

Nicolson, S. W. (1976b). The hormonal control of diuresis in the cabbage white butterfly, Pieris brassicae. J. exp. Biol. 65, 565-575.

Nishout, H. F. (1975). Excretory role of the midgut in larvae of the tobacco hornworm, Manduca sexta (L.). J. exp. Biol. 62, 221-230.

Rafaeli, A., Applebaum, S. W. and Moshitzky, P. (1986). An ACTH-like diuretic hormone in locusts. In Insect Neurochemistry and Neurophysiology, 1986 (ed. A. B. Borkovec and D. B. Gelman), pp. 355-357. New York: Humana Press.

Reynolds, S. E. AND Bellward, K. (1989). Water balance in Manduca sexta caterpillars: water recycling from the rectum. J. exp. Biol. 141, 33-45.

Rivier, J., Rivier, C. AND VALE, W. (1984). Synthetic competitive antagonists of corticotropin releasing factor: effect on ACTH secretion in rat. Science 224, 889-891.

Ryerse, J. S. (1978). Developmental changes in Malpighian tubule fluid transport. J. Insect Physiol. 24, 315-319.

Tam, J. P., Health, W. F. and Merrifield, R. B. (1983). $S_{N} 2$ deprotection of synthetic peptides with a low concentration of HF in dimethyl sulfide: evidence and application in peptide synthesis. J. Am. chem. Soc. 105, 6442-6455. 